\title{
METHODOLOGY FOR A MODEL-BASED CONTROL OF THE BOUNDARY ZONE PROPERTIES DURING MILLING OF TI-6AL-4V
}

\author{
M. Wimmer ${ }^{1 *}$, P. Rinck ${ }^{1}$, R. Kleinwort ${ }^{1}$, M. F. Zäh ${ }^{1}$ \\ ${ }^{1}$ Technical University of Munich, Institute for Machine Tools and Industrial Management, Garching, Germany \\ *Corresponding author; e-mail: Matthias.Wimmer@iwb.mw.tum.de
}

\begin{abstract}
A significant influencing factor which determines the strength, lifetime and reliability of a component after machining is the residual stress state in the boundary zone. A reliable adjustment of this condition during machining is currently not possible. It is desired to control the milling process using a model-based approach in order to generate defined geometries and residual stresses in titanium components simultaneously. This paper focuses on the influence of the process parameters on the residual stress state during the finishing operation of Ti-6Al-4V. The residual stress state was measured by $\mathrm{X}$-ray diffraction. During the process, the cutting forces and heat flow were measured. For mapping possible interactions and statistical influences, a statistically validated test plan was applied. The influence of the process parameters cutting speed, feed rate and axial depth of cut on the residual stress condition are shown. In order to take scattering material properties into account, the initial residual stress state and the material structure were determined by measurements prior to the machining process. In addition, the tool wear condition and the microgeometry of the tool are taken into account as an observable disturbance variable. These factors are analyzed with regard to the influence on the residual stress state.
\end{abstract}

\section{Keywords:}

Milling; Boundary zone properties; Internal stress states; Titanium; sensor tool holder; In-process measurement

\section{INTRODUCTION}

The continuing trend towards lightweight construction is increasingly leading to the use of high-strength construction materials. For example, high-temperature titanium alloys are used in gas and steam turbines to increase the maximum possible temperatures in the turbine - and thus its efficiency. In aerospace technology, titanium alloys Ti$6 \mathrm{Al}-4 \mathrm{~V}$ are used for the production of structural components due to their high strength and low mass per volume [Rotella 2014, Abboud 2015]. These components have to meet high quality standards in terms of fatigue strength and corrosion resistance. In order to fulfill increasing requirements, materials engineering is researching new, more resistant titanium alloys. In addition, optimized machining of titanium offers the possibility to further improve the component quality. A decisive influencing factor, which determines the strength of a component after machining, is the state of residual stress in the boundary zone [Yang et $\mathrm{Al}$ 2002]. During machining, residual stresses occur due to mechanical and thermal loads and, to a lesser extent, due to phase transformations.

In order to determine and dynamically control the residual stress condition of the component's boundary zone after machining of Ti-6Al-4V, it is necessary to model the applied mechanical process forces and the heat input into the process zone. These quantities can then be used to model the residual stress state [Huang 2015]. The primary goal is the model-based control of the Ti-6Al-4V milling process for the simultaneous adaptation of defined geometries and residual stress states. In order to achieve these goals, state-of-the-art methods have to be investigated and extended. A real-time capable analysis model has to be developed, which describes the relationship between the process parameters and the residual stress state. In addition, the tool wear condition as an observable disturbance variable and the scattering material properties of the raw parts as a hidden disturbance variable are considered. In order to be able to analytically map the complex relationship between the process control variables and the condition of the surface layer, a two-stage approach is chosen. The first step is the modelling of the heat and force input into the process zone. In a second step, the resulting residual stresses and the hardness curve in the component resulting from the machining are modelled. The resulting partial models are then coupled to form an overall model. The resulting real-time models can be used to determine the thermomechanical component loads during milling of Ti-6Al-4V. These form the basis for modeling the residual stress state and the hardness curve of the component boundary layer after machining. The coupled models can be used for the dynamic process control of the residual stress state. This includes the development and implementation of a suitable control concept and the testing of the control for robustness against perturbations.

First, the state of the art is analysed. Especially the boundary zone properties, which are changed by the cutting process, are characterized. Moreover, it is explained how residual stresses result in the component surface zone and 
how they influence it. In addition, the relationship between the individual process parameters during milling and the residual stress state, which influences the component lifetime, is shown. The process investigations for a comprehensive understanding of the interactions of process parameters and boundary layer conditions are described in section 3 . The machining center for carrying out the tests and the measuring equipment and methods used for force and temperature measurements are presented. Afterwards the existing methods for modelling the force and heat input induced into the component by the milling process are explained in more detail in section 4 . In addition, the limits of the modelling strategies and models already developed are shown. Section 5 summarizes the current status of the work. In addition, the concept of a newly developed sensor tool holder for in-process measurement of temperatures and cutting forces will be presented. Finally an overview of the further procedure for implementing the models in a suitable control concept in order to be able to specifically adjust the residual stresses during milling is given.

\section{STATE OF THE ART}

The machining of Ti-6Al-4V inevitably leads to changes in the surface and boundary zone properties due to the high mechanical and thermal component loads during the milling process. Surface properties include shape, roughness and surface topography. According to [Ozel 2010], the boundary zone properties are characterized by the following variables:

- Residual stress distribution

- Microstructure course

- Plastic deformations

- Changes in hardness

- Textures

- Cracks

Nowadays, the surface properties can be specifically adjusted during machining, but a process-safe adjustment of the edge zone properties, especially the residual stress state, is hardly possible [Sun 2009]. In the following, the influence of milling on the residual stress state of the workpiece is shown in more detail. Residual stresses are the mechanical stresses present inside a body without it being subjected to external mechanical or thermal loads. Residual stresses can be either tensile residual stresses or compressive residual stresses, whereby they are always in equilibrium within the body [Zanger 2012]. The residual stress condition of a component surface under load influences the component behaviour positively or negatively depending on the sign of the residual stresses, whereby the residual stress conditions at the surface are decisively responsible for the component service life [Sasahara 2005]. Residual compressive stresses in the component surface are to be preferred with regard to the resistance to component loads, since in that case applied tensile stresses must significantly exceed the amount of the residual compressive stresses before material damage in the form of microcracking can occur. During machining, tensile residual stresses are usually generated in the component boundary zone as a result of purely thermal stress. The friction between the tool and the workpiece (in particular the friction between the flank zone and the workpiece) causes the surface layer to heat up locally and expand in these areas, which initially induces residual compressive stresses. If the yield point of the material is exceeded by these stresses, a plastic compression occurs.
When the previously compressed edge layer cools down, it is stretched, leading to residual tensile stresses [Qin 2012]. A purely mechanical load on the component edge zone usually generates residual compressive stresses in the cutting direction by preventing elastic redeformation through already plastically deformed areas. During machining, thermally and mechanically induced residual stresses overlap and influence each other in a non-linear manner. Depending on which of the effects described shows the greater influence on the component boundary zone, tensile or compressive residual stresses are present after machining [Jawahir 2011, Davim 2010]. If titanium is machined, the resulting residual stresses after finishing are influenced by the process parameters cutting speed, feed per tooth, depth of cut and working engagement. In addition, the micro-geometry of the cutting edge significantly influences the resulting residual stresses. Compared to steel, there is only little literature available for $\mathrm{Ti}-6 \mathrm{Al}-4 \mathrm{~V}$, that describes the influence of the parameters mentioned above on the residual stress state. Some contradictory statements can even be found in the literature [Nespor 2015]. [Denkena 2014] have carried out an influence analysis on the main residual stresses during ball end milling of welded Ti-6Al-4V. They found out that the residual stress condition during the machining of Ti-6Al-4V is significantly dependent on the micro-geometry of the cutting edge. The cutting edge rounding has by far the greatest influence compared to the rake angle and the clearance angle. A larger cutting edge rounding causes higher residual compressive stresses in the workpiece. The process parameters have a smaller influence. In addition, it was demonstrated that the residual stress condition of the raw material and the thermally induced residual stresses are negligible in ball end milling. Thus, the residual stress condition is primarily determined by the mechanical component loads. However, [Nespor 2015] could not determine a direct correlation between the measured process forces and the residual stress state. Instead, the residual stresses correlated with the surface-generating cutting forces. These only take into account the part of the chip removal where the final surface is produced. A further publication deals with the influence of the process parameters and the determination of residual stress states during the machining of Ti-6Al-4V [Rotella 2014].

\section{MEASUREMENT TECHNOLOGY RESULTS}

By process investigations, a comprehensive understanding of the interactions between process parameters and surface layer conditions during milling of Ti-6Al-4V needs to be developed. Although the literature already contains statements on the fundamental relationships for Ti-6Al-4V, these cannot be easily transferred to this workpiece material-tool combination. Therefore, simple specimens with different process parameters have to be processed. Subsequently, downstream investigation methods such as X-ray diffractometry, the borehole method, micro- and ultramicrohardness measurements as well as light and electron microscopy have to be used to determine the influence of the process parameters on the residual stress state, hardness and microstructure. In addition, the wear condition and the microgeometry of the tool need to be analyzed with regard to their influence on the residual stress condition. In order to take scattering material properties into account, the initial residual stress condition and the material structure were determined by measurements prior to the machining process. Samples with varying process parameters were machined on 
a 5-axis machining center as the basis for the process investigations. The focus is on end milling processes. The aim was to cover the entire technically feasible parameter space. In order to be able to map possible interactions and statistical influences, a statistically validated test plan with repeatings was applied. The following process control variables are taken into account:

- $\quad$ Cutting speed $\mathrm{v}_{\mathrm{c}}$

- $\quad$ Feed per tooth $f_{z}$

- Axial depth of cut ap

- Radial depth of cut $a_{e}$

- Cutting radius $r_{s k}$

The experiments are repeated under different wear conditions of the tool in order to investigate the influence of this process disturbance variable. The flank wear is considered, which increases the contact surface between the flank zone and the workpiece, which significantly influences the heat input.

\subsection{GROB G350 5-axis milling machine}

The tests were carried out on a 5-axis universal machining center of type Grob G350. The tool, a four-toothed OptiMill titanium end mill from Mapal with a diameter of $12 \mathrm{~mm}$, was clamped using a hydraulic chuck. During the tests, the individual process parameters such as cutting speed $\mathrm{v}_{\mathrm{c}}$, feed per tooth $f_{z}$ and radial depth of cut ae were changed directly at the machine. In addition, two tools with different cutting edge roundings were used to investigate the influence of tool wear on the residual stresses.

\subsection{Force and temperature measurement in the workpiece}

In the following, the forces and temperatures during the machining of Ti-6Al-4V are investigated. Due to the poor thermal conductivity of titanium, a relatively large depth of cut was selected for peripheral milling as this leads to higher temperatures. In addition, this increases the effect of tool wear and the cutting forces.

\section{Force measurement}

A force measuring platform from Kistler (Model 9257A) was used to measure the cutting forces in the $X, Y$ and $Z$ directions with a sampling rate of $20 \mathrm{kHz}$. A vice was mounted on this platform to fix the workpiece during the machining process.

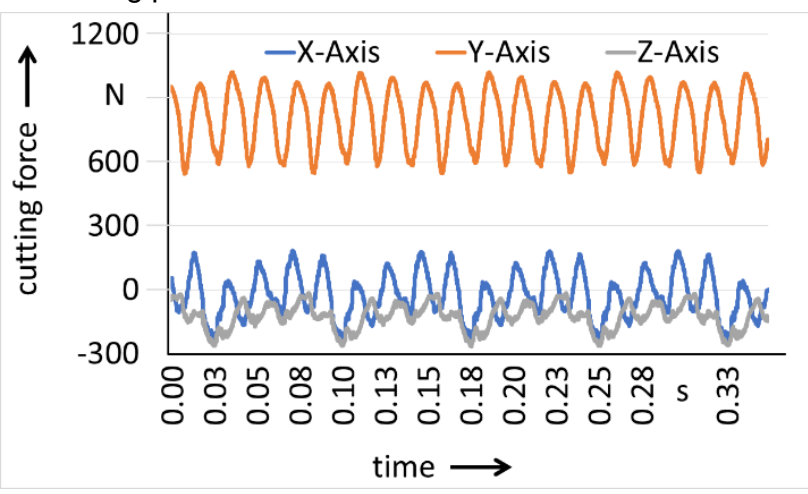

Fig. 1: Diagram of the cutting forces.

Figure 1 shows the individual cutting force components. Since full immersion end milling was used in the cutting tests, the $\mathrm{Y}$-force component, which acts vertically on the workpiece (orange), is most significant, which thus has the greatest influence on the resulting surface. To determine the residual stresses, the interaction between the affected surface and the number of cuts in the surface must be examined more closely.

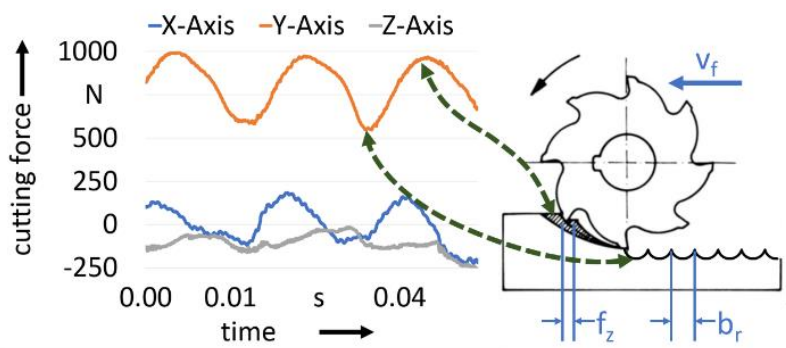

Fig. 2: Surface-generating force component.

As shown in Figure 2, most of the adjacent material in the engagement area is removed after the next rotation of the tool. The resulting surface is formed by cutting marks $b_{r}$ defined by the feed per tooth $f_{z}$ :

$b r=2 * f z$

This approach considers only the cross-section of the milling process that is in contact with the final surface. Thus, the introduction of residual stresses into the surface boundary zone is effected by the proportion of forces which generate the final chip stroke and are therefore referred to as surface-generating forces.

\section{Temperature measurement}

In order to measure the temperature during machining, temperature sensors were inserted into the shear zone. The calibration of the individual thermocouples was carried out by the manufacturer. For this purpose, the specimens were equipped with holes with a diameter of $0.6 \mathrm{~mm}$. In the next step, the sensors were coated with a special heat conducting paste, which improves the heat transfer between the sample body and the temperature sensor, and then introduced into the individual holes. The cutting axial depth of cut was reduced by $0.01 \mathrm{~mm}$ to prevent damage to the sensors during the milling process. This distance leads to the fact that the actual temperature in the shear zone has to be determined subsequently via the distance to the thermocouple with the help of the inverse heat conduction problem. In order to get as close as possible to the machining zone, the specimens were prepared so that the holes could be drilled vertically into the component. This was made possible by a $45^{\circ}$ inclined groove (Figure 3 ). The tool runs in this groove, which reduces the axial depth of cut and also the measurable cutting forces. Accordingly, temperature and cutting forces were not investigated in one experiment, but considered separately.
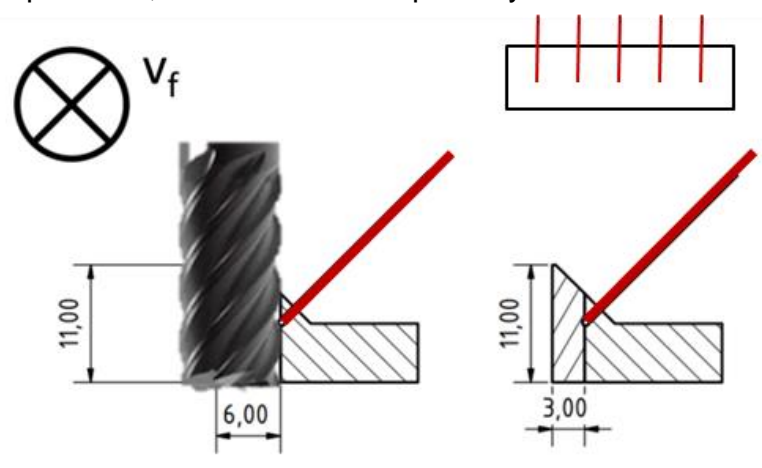

Fig. 3: CAD sectional view of the test specimen for the temperature measurement.

To support temperature measurement and data transmission, the sensors were connected to an $1 / O$ module coupled to a CompactDAQ chassis. The individual 
measurement signals were then evaluated and visualized via an Ethernet connection using a Matlab temperature measurement tool developed in-house. As measured values, the measuring tool outputs the temperatures of the individual sensors over time. The individual thermocouples were distributed evenly over the milling section at a defined distance $(15 \mathrm{~mm})$. For this reason, the respective temperature maxima are reached with a time shift (Figure $4)$.

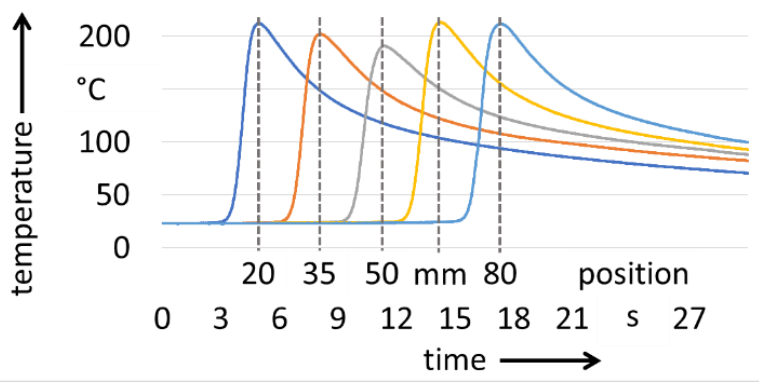

Fig. 4: Representation of the measured values of five temperature sensors of a machining test.

In order to be able to compare the temperatures of different experiments, the mean values of the maxima of all sensors in one experiment were calculated:

$\bar{T}_{\text {max }}=\frac{\sum_{i}^{n} \max \left(\text { Sensor }_{i}\right)}{n}$

To illustrate the influence of various parameters on the cutting temperature, the relative temperature change $\Delta T_{\text {re }}$ is given. It is calculated from the difference between the measured temperature of the initial experiment $T_{0}$ and the measured temperature of the actual cutting test. The formula is :

$\Delta T_{\text {rel }}=\frac{T_{i}-T_{0}}{T_{0}[K]}$

The machining parameters of the corresponding test, the averaged maximum temperatures of all sensors in ${ }^{\circ} \mathrm{C}$ and Kelvin, and the relative temperature are shown in Table 1. The relative temperature change is based on the measured values of the Kelvin unit.

Tab. 1: Overview of the temperature measurements.

\begin{tabular}{|c|c|c|c|c|}
\hline $\mathrm{Nr}$. & Experiment & $\begin{array}{l}\bar{T}_{\max } \\
{\left[{ }^{\circ} \mathrm{C}\right]}\end{array}$ & $\begin{array}{l}\bar{T}_{\max } \\
{[\mathrm{K}]}\end{array}$ & $\begin{array}{l}\Delta T_{\text {rel }} \\
{[\%]}\end{array}$ \\
\hline T0 & $\begin{array}{l}\text { Initial experiment } \\
\mathrm{f}_{\mathrm{z}}=0.04 \mathrm{~mm}, \mathrm{v}_{\mathrm{c}}=70 \mathrm{~m} / \mathrm{min}, \\
\mathrm{a}_{\mathrm{e}}=3 \mathrm{~mm}, \mathrm{r}_{\mathrm{sk}}=5.4 \mu \mathrm{m}\end{array}$ & 136 & 406 & - \\
\hline $\mathrm{T} 1$ & $\begin{array}{l}\mathbf{f}_{\mathbf{z}}=\mathbf{0 . 0 8} \mathbf{\mathrm { mm }}, \\
\mathrm{v}_{\mathrm{c}}=70 \mathrm{~m} / \mathrm{min}, \\
\mathrm{a}_{\mathrm{e}}=3 \mathrm{~mm}, \mathrm{r}_{\mathrm{sk}}=5.4 \mu \mathrm{m}\end{array}$ & 106 & 379 & -7.4 \\
\hline T2 & 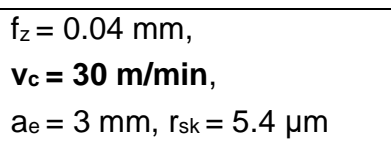 & 204 & 477 & +16.7 \\
\hline T3 & $\begin{array}{l}\mathrm{f}_{\mathrm{z}}=0.04 \mathrm{~mm}, \mathrm{v}_{\mathrm{c}}=70 \mathrm{~m} / \mathrm{min} \\
\mathrm{a}_{\mathrm{e}}=6 \mathrm{~mm}, \mathrm{r}_{\mathrm{sk}}=5.4 \mu \mathrm{m}\end{array}$ & 141 & 414 & +1.2 \\
\hline T4 & $\begin{array}{l}\mathrm{f}_{\mathrm{z}}=0.04 \mathrm{~mm}, \mathrm{v}_{\mathrm{c}}=70 \mathrm{~m} / \mathrm{min} \\
\mathrm{a}_{\mathrm{e}}=3 \mathrm{~mm}, \mathbf{r}_{\mathrm{sk}}=\mathbf{1 6 . 5} \boldsymbol{\mu \mathrm { m }}\end{array}$ & 206 & 479 & +17.2 \\
\hline
\end{tabular}

\subsection{Effects on the superficial residual stress}

First, the influence of the variation of the different process parameters on the heat and force input in the process zone was analysed. Table 2 shows how the individual parameters were changed in the experiments.

Tab. 2: Effects on temperature and cutting force.

\begin{tabular}{|c|c|c|c|}
\hline \multicolumn{2}{|c|}{$\begin{array}{c}\text { Increase of the } \\
\text { parameter }\end{array}$} & $\begin{array}{c}\text { Effect on } \\
\text { temperature in } \mathrm{K}\end{array}$ & $\begin{array}{c}\text { Effect on } \\
\text { cutting force in } \\
\mathrm{N}\end{array}$ \\
\hline $\mathrm{v}_{\mathrm{c}}$ & $30-70 \mathrm{~m} / \mathrm{min}$ & -68 & -55 \\
\hline $\mathrm{a}_{\mathrm{e}}$ & $3-6 \mathrm{~mm}$ & +5 & +565 \\
\hline $\mathrm{r}_{\mathrm{sk}}$ & $5.4-16.5 \mu \mathrm{m}$ & +70 & +525 \\
\hline $\mathrm{f}_{\mathrm{z}}$ & $0.04-0.08 \mathrm{~mm}$ & -30 & +403 \\
\hline
\end{tabular}

It can be seen that every change of a parameter leads to a change of temperature and force at the same time. However, this relationship is not proportional, as the variation of $f_{z}$ shows. Subsequently, the residual stresses close to the surface in the processed experiment samples were measured by X-ray diffraction. For the four different parameters investigated, figure 5 shows the effect on the superficial residual stress in the boundary layer zone.

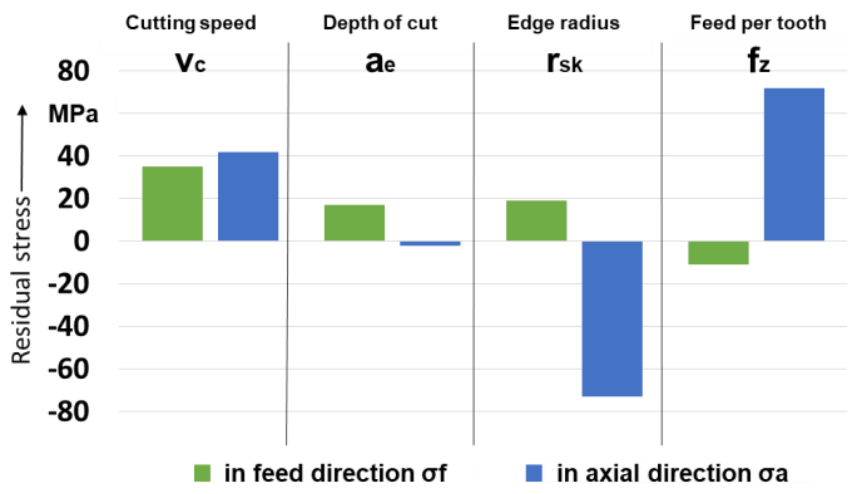

Fig. 5: Effects on the superficial residual stress.

Increasing the cutting speed $v_{c}$ leads to higher residual tensile stresses. It can also be observed that a larger cutting edge rounding $r_{\text {sk }}$ leads to an increase in residual compressive stresses in the axial milling direction $\sigma_{a}$. However, residual tensile stresses are induced in the feed direction. The opposite is observed, if the feed per tooth is increased. This results in an induction of of residual compressive stresses in the axial direction. In addition, the increase in the depth of cuthas a small influence on the residual stresses close to the surface.

\section{THERMOMECHANICAL MODEL}

In order to determine the residual stress state of the component edge zone after machining of Ti-6Al-4V, it is necessary to model the mechanical process forces and the heat input into the process zone. The resulting partial models are then coupled to form an overall model. In the following, it will be shown which methods are used to 
determine these parameters today and where the current challenges are.

\subsection{Cutting force model}

The modelling of machining processes focuses on the area of cutting force components. Today, the description of the cutting force is usually carried out on the basis of empirical formulations according to [Kienzle 1952], process-specific forms derived from them or analytical models based on the theory of plasticity [Denkena 2014]. Furthermore, numerical computational methods based mainly on the finite element method (FEM) have been increasingly used in recent years. In the empirical models, a regressive determination of the cutting force coefficients is carried out from experimentally determined data. A disadvantage of that is the narrow limitation of the validity range to the machining case set during data acquisition. Since the publication of the cutting force relations of [Kienzle 1952] a large number of investigations have been carried out for the most diverse machining cases, so that today extensive tables with specific cutting force values and process-specific correction factors exist [König 1982]. Analytical models are mostly based on laws from the theory of plasticity and are based on the plane deformation state of the orthogonal section [Altintas 2014]. In the shear plane model, the chip formation is regarded as an ideal plastic forming of the material within a plane surface in front of the tool's cutting edge. Shear zone models describe an area of plastic deformation limited by curves and thus have the advantage that the hardening and softening of the material can be included. The deviations between the analytical models and reality, which result from simplyfying assumptions, are still problematic [Wang 2017]. In addition, there are approaches with which analytical models can be extended by the influence of the cutting edge micro-geometry and the wear condition of the tool [Sun 2013]. These variables influence the state of residual stress after the cutting process and must therefore be taken into account during modeling. Numerical calculation methods are particularly suitable for determining process variables that cannot be measured or can only be investigated with considerable effort. In the FEM simulation, stress and temperature distributions can be determined both in the deformation zones and on the cutting edge [Ee 2005]. Thereby, the purely thermal models, in which the energy conservation equation is solved, compete with the coupled mechanical-thermal models, which additionally consider the elastoplastic solid-state mechanics. For the latter, the heat dissipated part of the mechanical forming energy is transferred as a local heat source term to the energy conservation equation [Mamedov 2015]. Compared to empirical and analytical models, the computational effort for FEM simulations is usually high, which makes them unsuitable for dynamic process control.

\subsection{Heat flow model}

Although a large part of the heat generated in the cutting zone is dissipated via the chips and the tool [Milberg 1992], the heat input into the workpiece can significantly influence the component quality [Schweinoch 2015]. This applies in particular to dry machining, where the use of cooling lubricants is completely omitted. The simulation of thermomechanical interactions is a highly complex task requiring suitable models and modelling strategies. According to the current state of research, most of these are not available with the required accuracy or can only be applied to a limited extent. Thus, a holistic investigation and optimization of cutting processes is currently not possible. Modelling strategies for the heat flow already exist, which include analytical and empirical models up to numerical approaches, which are mostly based on the FE method. In order to achieve a better compromise between accuracy and computational efficiency, the different approaches are often combined. One possibility for mathematical modelling of the milling process is based on a rigid multi-body model of the machine structure and a thermoelastic continuum model of the workpiece [Rott 2008]. The coupling of an FE workpiece model with analytical cutting force and heat source models basically allows the prediction of temperature distributions and stresses in the component and of the deformation behaviour [Rai 2008]. The achievable accuracies depend on the degree of discretization and parameterization of the models used. In particular, the description of the process heat source using analytical or empirical approaches poses a major problem. On the one hand, this is due to the lack of accessibility of the heat-affected zone in machining processes for metrological investigations, which makes precise model parameterization more difficult. On the other hand, important influencing factors, such as the wear condition of the tool, can often only be represented insufficiently in models. Various machining processes were investigated with regard to thermomechanical interactions and suitable simulation tools [Biermann 2015]. In addition to turning, grinding and drilling processes, milling processes in particular were considered. The focus was on different process aspects and applications. This is also reflected in the modelling strategies and models developed, some of which have to meet completely different requirements.

\section{CONCLUSION AND OUTLOOK}

As current state of the art, there are already numerous studies that describe the influence of cutting parameters on the residual stress state of the workpiece. Until now, thermo-mechanical models with regard to tool wear in combination with a model of the resulting residual stress distribution after machining of Ti-6Al-4V have not been considered holistically. Furthermore, it is not yet possible to control the resulting residual stress distribution on the basis of in-process measurements. For this reason, the approach chosen in this research is to implement a sensor tool holder for measuring the cutting forces and temperature directly at the tool during the cutting process. The measured values serve as input for modelling the residual stress state of the component boundary layer after machining and can thus be used in the future for process control of the residual stress state. This requires the development and implementation of a suitable control concept and the testing of the control for robustness. In addition, the models and the controller can be extended by further manipulated variables. In addition to the conventional process parameters already considered, this also includes, for example, the influence of the tool inclination angle. In addition, the results can be transferred to other application areas, e.g. the milling of thin-walled components.

\section{ACKNOWLEDGMENTS}

Our thanks go to the German Research Foundation (DFG) for funding the project «Model-based determination of the boundary zone properties during milling of Ti-6Al-4V » within the framework of the priority program 2086 « Surface conditioning in machining processes $"$.

\section{REFERENCES}

[Abboud 2015] Abboud, E. Characterization of MachiningInduced Residual Stresses in Titanium-Based Alloys. Dissertation McGill University of Quebec, 2015. 
[Altintas 2014] Altintas, Y., Kersting, P., Biermann, D., Budak, E., Denkena, B., Lazoglu, I. Virtual process systems for part machining operations. In: CIRP Annals Manufacturing Technology 63, 2014, pp. 585-605.

[Biermann 2015] Biermann, D., lovkov, I. Modelling, simulation and compensation of thermal effects for complex machining processes. Production Engineering 9, 2015, pp. 433-435.

[Davim 2010] Davim, J. Surface integrity in machining. London: Springer, 2010.

[Rott 2008] Rott, O., Rasper, P., Hoemberg, D. A milling model with thermal effects including the dynamics of machine and workpiece. Intenational Conference on Process Machine Interactions, Berlin, 2008.

[Denkena 2014] Denkena B., Nespor, D., Boess, V., Koehler J. Residual stresses formation after re-contouring of welded Ti-6Al-4V parts by means of 5 -axis ball nose end milling. CIRP Journal of Manufacturing Science and Technology, 2014.

[Ee 2005] Ee, K.C., Dillon Jr., O.W., Jawahir I.S. Finite element modeling of residual stresses in machining induced by cutting using a tool with finite edge radius. International Journal of Mechanical Sciences, 2005.

[Huang 2015] Huang, X., Zhang, X., Ding, H. An Analytical Model of Residual Stress for Flank Milling of Ti-6Al-4V. In: Procedia CIRP 31, 2015, pp. 287-292.

[Jawahir 2011] Jawahir, I. S., Brinksmeier, E., M'Saoubi, R., Aspinwall, D. K., Outeiro, J. C., Meyer, D., Umbrello, D., Jayal, A. D. Surface integrity in material removal processes: Recent advances. In: CIRP Annals - Manufacturing Technology, 2011, pp. 603-626.

[Kienzle 1952] Kienzle, O., Viktor H. Die Bestimmung von Kräften und Leistungen an spanenden Werkzeugen und Werkzeugmaschinen. VDI-Z 94, 1952, pp. 299-305.

[König 1982] König, W., Essel, K., Witte, L. Spezifische Schnittkraftwerte für die Zerspanung metallischer Werkstoffe. Düsseldorf: Stahleisen mbH, 1982.

[Mamedov 2015] Mamedov, A., Lazoglu I. Thermal Analysis of micro milling titanium alloy Ti-6Al-4V. In: Journal of Materials Processing Technology, 2015.

[Milberg 1992] Milberg, J. Werkzeugmaschinen Grundlagen. Zerspantechnik, Dynamik, Baugruppen und Steuerungen. Berlin, Heidelberg: Springer Berlin Heidelberg, 1992.

[Nespor 2015] Nespor, D. Randzonenbeeinflussung durch die Rekonturierumg komplexer Investitionsgüter aus Ti-6Al4V, Dissertation Gottfried Wilhelm Leibniz University Hannover, 2015.
[Ozel 2010] Ozel T., Durul U. Machining induced surface integrity in titanium and nickel alloys. In: International Journal of Machine Tools \& Manufacture, 2010.

[Qin 2012] Qin, M.Y., Ye, B.Y., Wu, B. Investigation into influence of cutting fluid and liquid nitrogen on machined surface residual stress. Adv. Mater. Res. 566, 2012, pp. 710.

[Rai 2008] Rai J.K. Finite element method based machining simulation environment for analyzing part errors induced during milling of thin-walled components. International Journal of Machine Tools and Manufacture, 2008.

[Rotella 2014] Rotella, G., Dillon, O. W., Umbrello, D., Settineri, L., Jawahir, I. S. The effects of cooling conditions on surface integrity in machining of Ti6Al4V alloy. In: The International Journal of Advanced Manufacturing Technology, 2014, pp. 47-55.

[Sasahara 2005] Sasahara, $H$. The effect on fatigue life of residual stress and surface hardness resulting from different cutting conditions of $0.45 \% \mathrm{C}$ steel. Int. J. Mach. Tools Manuf. 45, 2005, pp. 131-136.

[Schweinoch 2015] Schweinoch, M., Joliet, R., Kersting, P. Predicting thermal loading in NC milling processes. In: Production Engineering 9, 2015, pp. 179-186.

[Sun 2009] Sun, J., Guo, Y. A comprehensive experimental study on surface integrity by end milling Ti-6Al-4V. In: Journal of Materials Processing Technology 209, 2009, pp. 4036-4042.

[Sun 2013] Sun, Y., Sun, J., Li, J., Li, W. Feng, B. Modeling of cutting force under the tool flank wear effect in end milling Ti6AI4V with solid carbide tool. In: The International Journal of advanced Manufacturing Technology, 2013, pp. 25452553.

[Wang 2017] Wang J., Zhang D., Wu B., Luo M. Numerical and empirical modelling of machining-induced residual stresses in ball end milling of Inconel 781. In: Procedia CIRP 58, 2017.

[Yang 2002] Yang, X., Richard L., Grandt, A. F. An Experimental Study on Fatigue Life Variance, Residual Stress Variance, and Their Correlation of Face-Turned and Ground Ti 6Al-4V Samples. In: Journal of Manufacturing Science and Engineering, 2002.

[Zanger 2012] Zanger, F. Segmentspanbildung, Werkzeugverschleiß, Randschichtzustand und Bauteileigenschaft. Dissertation Karlsruher Institut für Technologie, 2012. 